\title{
The Impacts of Topography on Spatial and Temporal Rainfall Distribution over Rwanda Based on WRF Model
}

\author{
Didier Ntwali ${ }^{1,2,3}{ }^{*}$, Bob Alex Ogwang ${ }^{4,5}$, Victor Ongoma ${ }^{4}$ \\ ${ }^{1}$ Institute of Atmospheric Physics, Chinese Academy of Sciences, Beijing, China \\ ${ }^{2}$ University of Chinese Academy of Sciences, Beijing, China \\ ${ }^{3}$ Rwanda Meteorology Agency, Ministry of Natural Resources (MINIRENA), Kigali, Rwanda \\ ${ }^{4}$ Nanjing University of Information, Science and Technology, Nanjing, China \\ ${ }^{5}$ Uganda National Meteorological Authority, Kampala, Uganda \\ Email: *ntwalididi@yahoo.fr, ntwalididier@mail.iap.ac.cn
}

Received 13 January 2016; accepted 26 February 2016; published 1 March 2016

Copyright (C) 2016 by authors and Scientific Research Publishing Inc.

This work is licensed under the Creative Commons Attribution International License (CC BY). http://creativecommons.org/licenses/by/4.0/

cc) (i) Open Access

\section{Abstract}

The impact of topography on heavy rainfall during two rain seasons was investigated in order to explain their mechanisms on rainfall distribution over Rwanda. Weather Research and Forecasting (WRF-ARW) model was used to study two historical cases of heavy rainfall which took place over Rwanda during two rain seasons, March to May (MAM) and September to December (SOND), from April 7 to 9, 2012 (for MAM) and from October 29 to 31, 2012 (during SOND). The control experiment was done with actual topography, whereas sensitivity experiment was carried out with topography reduced by half. Results show that rainfall distribution over Rwanda significantly changes when topography is reduced. The reduction in topography leads to a decrease in rainfall amounts in both MAM and SOND seasons, with varying magnitudes. This reveals the importance of orography in determining rainfall amounts and distribution over the region. The accumulated rainfall amount from WRF underestimate or overestimate rain gauge stations data by region and by season, but there is good agreement especially in altitude below $1490 \mathrm{~m}$ and above $1554 \mathrm{~m}$ during April and October respectively. The results may motivate modelling carters to further improve parameterization schemes in the mountainous regions.

\section{Keywords}

Topography, Seasonal Rainfall, Rwanda, WRF Model

\footnotetext{
${ }^{*}$ Corresponding author.
}

How to cite this paper: Ntwali, D., Ogwang, B.A. and Ongoma, V. (2016) The Impacts of Topography on Spatial and Temporal Rainfall Distribution over Rwanda Based on WRF Model. Atmospheric and Climate Sciences, 6, 145-157. 


\section{Introduction}

Rwanda is a country with high altitude located in East Africa, where rainfall is the most important climate variable. The large-scale tropical climate in East Africa is characterized by convergence zones and regional factors associated with complex terrain, several vegetation types, and lakes [1]. It experiences four seasons: two rain seasons and two dry seasons. The two rain seasons are September to December (SOND), locally referred to as short rain season and March to May (MAM), locally known as long rain season. The general aim of this study was to simulate heavy rainfall events using WRF model to investigate the influence of topography during two rainfall seasons in Rwanda. Two days which were characterized by heavy rainfall and strong winds have been taken as case studies: 09 April 2012 and 30 October 2012. Due to heavy rainfall and strong winds in those days, topography of all regions in Rwanda has been taken into consideration and the analysis was mainly done over regions with high altitude located in northern and western provinces. In the previous study they found that regions in the northern and western provinces (high altitude regions) have higher amount of rainfall compared to other regions (low altitude regions) such as eastern province [2]. There exists a relationship between elevation and spatial and temporal rainfall [3]. In their empirical model in Kenya (East Africa), elevation was found to be the only significant topographic predictor of mean annual precipitation. In a study on Alberta floods of June 2005, showed that there are dependent on the presence of Rocky Mountains for their severity [4]. With reducedmountain elevations, their WRF results gave a reduction in maximum precipitation rates over the mountain and foothills by $50 \%$, where precipitation in the flood-affected basins reduced by $15 \%$ - $45 \%$. They showed that the reduction in amount of precipitation is explained by the decrease in orographic lifting over the reduced-mountain terrain. For large mountain ranges, precipitation maximizes over the windward slopes, whereas for smaller hills the maximum tends to occur near the crest [5]. It has also been noted that topography influences precipitation patterns by altering both local wind distributions and the condensation of precipitable water [6]. Over East Africa, a number of factors contribute to seasonal rainfall. For example during MAM season, moisture transport is governed by Intertropical Convergence Zone (ITCZ) which shifts from south to north, and the Atlantic and Congo air mass, which is usually accompanied by strong southerly winds. Indian Ocean drives east African rainfall, where Rwanda is located by altering the Walker circulation [7]. Comparing to other tropical regions, east African region is disproportionately covered by large and many inland lakes, which provide a suitable geographical setting for the interaction between large scale climate systems and lake-induced mesoscale flows. The relationship between rainfall, altitude and distance from the sea in the Freetown Peninsula, Sierra Leone, where their results showed significant differences between ocean-facing and rain-shadow stations; the rainfall amount increased with distance from the sea, since terrain at higher altitude regions was far from the sea than at lower altitude regions [8]. The Congo air mass which is humid significantly enhances convection and rainfall amounts received in the northwestern and western regions of the Lake Victoria [9]. There is an interaction between east African regional climate and Lake Victoria which is located in Northeast of Rwanda at all-time scales, including past climates [10]. During SOND season, the ITCZ shifts from North to South and the region is dominated by northerly and westerly winds, accompanied by the Congo air mass which brings moisture into Rwanda. The Congo air mass flow is humid, convergent and thermally unstable, which results into rainfall. The intensification of synoptic systems shows the sources and the origin of moisture injection [11] in all regions of Rwanda, along with movement of ITCZ. In general, the main factors influencing Rwanda' s rainfall are: 1) Subtropical anticyclones; 2) Congo air mass; 3) Inter-seasonal wave variation; 4) The Mascarene, Azores, St. Helena and Arabian high-pressure systems; 5) Regional topography, large water bodies (e.g. Lake Kivu), and large forests. Downscaling is one of the main issues in east Africa because of the complex topography which includes several high mountains, elongated ridges and escarpments paralleling the faults of the East African Rift system, with many large lakes in contrasted topographical settings [12]. WRF model has been used in different regions by a number of researchers. For example, as a mesoscale model, WRF was shown to have the ability to reproduce the surface wind direction over complex terrain [13]. The model gives room for the selection of a large panel of physical schemes [14]. It is helpful in weather forecasting, especially over complex terrain and it is generally suitable for a broad application, with scales ranging from meters to thousands kilometers [15]. Rwanda has a tropical temperate climate because of its high elevation. The Albertine branch of the Rift Valley runs along the western side of Rwanda and much of the border with Democratic Republic of Congo (DRC) is mountainous with elevation over $2000 \mathrm{~m}$ [2]. Elevation reduces towards the central plateau (1500 - $2000 \mathrm{~m}$ ) of Rwanda and in the eastern plateau towards the border with Tanzania $(<1500 \mathrm{~m})$. Rwanda’s high altitude regions are located in northern and 
western provinces and low altitudes are located in eastern and southern provinces (Figure 2(b)). Rwanda has a bimodal pattern of rainfall, driven primarily by the movement of the ITCZ, which is a zone where the north-easterly and south-easterly trade winds converge and form a belt of low pressure and hence rainfall [16]. The ITCZ moves from southern to northern tropics and back through the course of the calendar year; the long rain season is experienced during March to May as the ITCZ moves north and the short rain season (SOND) occur on its return to the south. The onset of the short rains in East Africa occurs usually in October and its precipitation exhibits complicated patterns of temporal and spatial distributions where regions have significant different amount of precipitation [1]. Large-scale precipitation in the region is mainly initiated from the southeastern and eastern Indian Ocean monsoon flow which brings moisture into east Africa. Topography has a significant effect on spatial patterns of rainfall both regionally and globally [17]. In East of Africa high rainfall amount occur at high elevations due to forced convection, Lake Victoria's moisture and the mountains which act as barrier to winds which transport moisture [18]. The new findings of this study are the different impacts of mountains on the rainfall amount spatial distribution in different provinces of Rwanda and which may change by seasons. The WRF model shows the ability to forecast rainfall distribution in high mountains regions than regions with low mountains of Rwanda. This shows the role of using WRF model in weather forecasting in Rwanda which is well known as a country with many high mountains.

\section{Model Setup and Experimental Design}

In this study, the Weather Research and Forecasting (WRF-ARW) model was used to investigate the influence of topography on precipitation in Rwanda, as in [19]. The Weather Research and Forecasting (WRF) model is considered as the latest and widely used mesoscale models which is used by both operational and research communities [20]. The Advanced Research WRF (ARW) is the main component of the WRF modeling system in which there are several initialization programs for idealized and real-data simulations. There is a fully compressible, Eulerian and non-hydrostatic equations with a run-time hydrostatic option which are conservative for scalar variables in the ARW dynamical core [21]. The WRF model has the ability to simulate extreme weather events or events of short time [22]. It provides several parameterization options named as microphysics, cumulus parameterization, surface layer, land surface model and planetary boundary layer [21]. The WRF model uses the terrain-following, hydrostatic-pressure vertical coordinate with constant pressure surface as top of the model boundary. The third order Runge-Kutta scheme while the spatial discretization employs 2nd- to 6th-order advection options. The model has several initial, lateral and top boundaries [23] and it can use the interactive one-way, two-way, and moving nesting options [24].

The WRF model based surface rainfall is governed by equations for water species [25] expressed as:

$$
\begin{gathered}
\frac{\partial\left(\rho_{a} Q_{v}\right)}{\partial t}=A D V_{Q_{v}}+D I F F_{Q_{v}}+E_{S}+\rho_{a} S_{Q_{v}}, \\
\frac{\partial\left(\rho_{a} Q_{c}\right)}{\partial t}=A D V_{Q_{c}}+D I F F_{Q_{c}}+\rho_{a} V_{Q_{c}}, \\
\frac{\partial\left(\rho_{a} Q_{c}\right)}{\partial t}=A D V_{Q_{x}}+D I F F_{Q_{x}}+S E D I_{Q_{x}}+\rho_{a} V_{Q_{x}}, x \in(r, i, s, g, h)
\end{gathered}
$$

In the Equations (1), (2) and (3) the 3D advection terms are defined as:

$$
A D V_{Q_{v}}=-\nabla_{3} \cdot\left(\rho_{a} Q_{v} V\right), A D V_{Q_{c}}=-\nabla_{3} \cdot\left(\rho_{a} Q_{c} V\right) \text {, and } A D V_{Q_{x}}=-\nabla_{3} \cdot\left(\rho_{a} Q_{x} V\right)
$$

The sedimentation term is defined as:

$$
S E D I_{Q_{x}}=\frac{\partial\left(\rho_{a} Q_{x} V_{Q_{x}}\right)}{\partial z}
$$

where $Q_{v}, Q_{c}$ and $Q_{x}$ are the mixing rations of water species ( $v$ : water vapor; c: cloud water; $r$ : rain water; $i$ : cloud ice; s: snow; $g$ : graupel; $h$ : hail), $E_{S}$ is the surface moisture flux, $\rho_{a}$ is the air density, $V$ is the 3D wind vector, $V_{Q_{x}}$ is the mass weighted terminal particle fall speed, $S_{Q_{v}}, S_{Q_{c}}$, and $S_{Q_{x}}$ are source and sink terms. 
The model was used to study two historical cases of heavy rainfall which took place over Rwanda during two rain seasons, March to May (MAM) and September to December (SOND), from April 7 to 9, 2012 (for MAM, later referred to as CASE-I) and from October 29 to 31, 2012 (during SOND, later referred to as CASE-II). The two cases were chosen because the extreme rainfall events during the two periods caused a lot of disaster in Rwanda. Two sets of experiments were done. The control experiment was done with actual topography (RAT), whereas sensitivity experiment was carried out with topography reduced by half (RRT). This was done to examine the sensitivity of rainfall distribution in Rwanda to topography during the two rain seasons. The initial and boundary conditions for the WRF model simulations were determined by 6 hourly, NCEP FNL (Final) Operational Global Analysis data. The simulations were performed in three nested domains (Figure 1(a)), with spatial resolution of $36 \mathrm{~km}$ (large domain), $12 \mathrm{~km}$ (medium domain) and $4 \mathrm{~km}$ (small domain) by considering topography elevation (Figure 1(b)) in Rwandan provinces (Figure 1(c)). The WRF Domain Wizard was used for the suitable configuration of the domain of interest.

The test of WRF capability in simulating the atmospheric water cycle over Equatorial Africa showed that KF (Kain-Fritsch) scheme produced the lowest RMS errors, especially when combined with the YSU or ACM2 PBL schemes [26]. Various configurations of the model with 3 nesting and physical parameterization schemes (Table 1) were used in order to get a suitable design for a regional atmospheric reanalysis.

Due to the impacts the large scale may have on small scale, the large domain is used in order to capture the impacts of Indian Ocean, Atlantic Ocean, Mascarene, Azores, St. Helena and Arabian high-pressure systems. Regions in Rwanda with high altitude (mountains) have been considered in order to understand the influence of topography on rainfall. In the previous study the WRF results was close to ground measurements respectively [27]. The topography was reduced by half for regions located in the 3 domains, where the analysis was focused on high altitudes regions in Rwanda (Table 2).

We have used 10 rain gauges daily data which were available from Rwanda meteorological stations located across the country shown in Table 3 in order to evaluate the WRF model accuracy and which regions by season

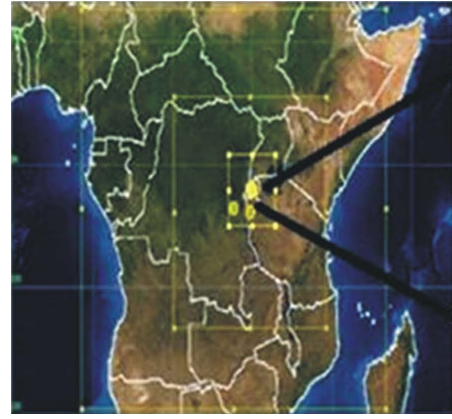

(a)

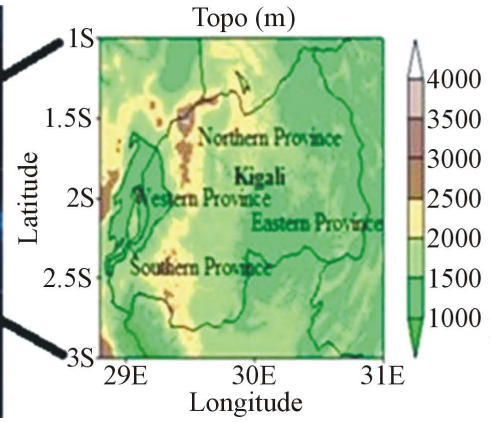

(b)

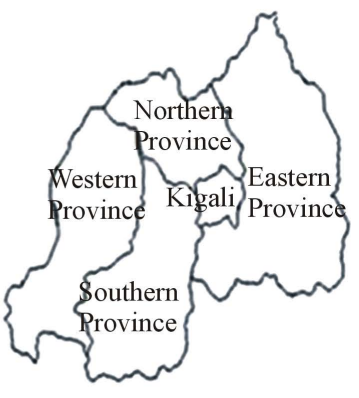

(c)

Figure 1. Three model domains used in the study (a) topography elevation (m) and location of Rwandan provinces (c).

Table 1. The model configuration.

\begin{tabular}{cc}
\hline Parameterization & Choice \\
\hline Cloud microphysics & WSM 3-class simple ice scheme \\
Longwave radiation & rrtm scheme \\
Shortwave radiation & Dudhia scheme \\
Surface layer & MM5 Monin-Obukhov scheme \\
Land layer & Unified Noah Land-surface model \\
Planetary boundary layer & YSU scheme \\
Cumulus option & Kain-Fritsch (new Eta) scheme \\
\hline
\end{tabular}


Table 2. High altitude regions in the north and western provinces of Rwanda.

\begin{tabular}{ccccc}
\hline High altitude regions & Location & Elevation & Lat & Lon \\
\hline Mount Karisimbi & Northern province & $4510 \mathrm{~m}$ & -1.50 & 29.44 \\
Mount Muhabura & Northern province & $4127 \mathrm{~m}$ & -1.23 & 29.40 \\
Mount Gahinga & Northern province & $3474 \mathrm{~m}$ & -1.23 & 29.38 \\
Nyungwe Forest & South-Western province & $1600-2950 \mathrm{~m}$ & -2.5 & 29.42 \\
Mount Muhungwe & Western province & $2928 \mathrm{~m}$ & -1.67 & 29.38 \\
Mount Rutare & Western province & $2884 \mathrm{~m}$ & -1.76 & 29.46 \\
Mount Kwiruhelo & Western province & $2776 \mathrm{~m}$ & -1.54 & 29.25 \\
Mount Remera & Western province & $2519 \mathrm{~m}$ & -1.56 & 29.26 \\
Mount Kabuye & Northern province & $2643 \mathrm{~m}$ & -1.60 & 29.81 \\
Mount Mutake & Northern province & $2378 \mathrm{~m}$ & -1.52 & 29.29 \\
Mount Gihinga & Northern province & $2369 \mathrm{~m}$ & -1.56 & 29.29 \\
Mount Murarambwe & Western province & $2327 \mathrm{~m}$ & -2.16 & 29.18 \\
Mount Kamabuye & Northern province & $1828 \mathrm{~m}$ & -1.55 & 29.20 \\
\hline
\end{tabular}

Table 3. Rain gauges stations by province.

\begin{tabular}{|c|c|c|c|c|}
\hline Meteorological stations & Province & Lat & Lon & Elevation \\
\hline Byumba & Northern province (NP) & -1.36 & 30.03 & $2235 \mathrm{~m}$ \\
\hline Busogo & Northern province (NP) & -1.58 & 29.55 & $2100 \mathrm{~m}$ \\
\hline Gikongoro & Southern province (SP) & -2.48 & 29.56 & $1930 \mathrm{~m}$ \\
\hline Ruhengeri & Northern province (NP) & -1.5 & 29.6 & $1878 \mathrm{~m}$ \\
\hline Kamembe & Western province (WP) & -2.46 & 28.91 & $1591 \mathrm{~m}$ \\
\hline Gisenyi & Northern province (NP) & -1.66 & 29.25 & $1554 \mathrm{~m}$ \\
\hline Kigali Airport & Kigali (K) & -1.96 & 30.13 & $1490 \mathrm{~m}$ \\
\hline Gitega & Kigali (K) & -1.57 & 30.04 & $1474 \mathrm{~m}$ \\
\hline Kawangire & Eastern province (EP) & -1.49 & 30.27 & $1473 \mathrm{~m}$ \\
\hline Nyagatare & Eastern province (EP) & -1.33 & 30.33 & $1450 \mathrm{~m}$ \\
\hline
\end{tabular}

the model shows significant agreement. Due to the few availability of rain gauges stations data, we used 6 and 9 stations during April and October respectively for analysis.

It is worth noting that the regions facing the windward slope are wetter due to air which is forced up the slope and gets cooler. Since cooler air can hold less moisture than warm air, it results into rainfall. On the leeward side, the opposite process occurs. This is because as air is forced down the slope, it gets warmer. As an air parcel rises, it has the ability to carry water vapor, which is a fundamental process in orographic precipitation [27].

\section{Results and Discussion}

\subsection{Rainfall Analysis}

In order to understand the influence of topography on rainfall over high altitude regions, we examine the mean rainfall in the respective regions for simulations with actual topography and with reduced topography for the 
two cases, CASE-I (Figure 2(a)) and CASE-II (Figure 2(b)). Figure 5 reveals that when topography elevation is reduced, there is a general reduction in rainfall in most regions, with 3 regions exhibiting an increase in rainfall. The overall mean rainfall however for CASE-I, considering all the regions reveals that there is a marked reduction in rainfall when topography is reduced, where the mean rainfall for simulation with actual topography is $39.4 \mathrm{~mm}$, whereas that with reduced topography is $30.2 \mathrm{~mm}$.

The reduction in rainfall may be associated with the change in wind direction, which alters moisture transport in the different regions. On the other hand, during SOND season (CASE-II, (Figure 2(b)), most of the regions showed an increase in the mean rainfall when topography elevation is reduced by half, as oppose to CASE-I. A few regions however showed a decrease in the mean rainfall when topography is reduced. In Figure 3 the accumulated rainfall (mm) for WRF with actual topography (AT) (Figure 3(a), Figure 3(d)), WRF with reduced topography (RT) (Figure 3(b), Figure 3(e)) and difference between actual and reduced topography (AT-RT) (Figure 3(c), Figure 3(f)) for the period from April 7 to 9 and October 29 to 31, 2012 respectively. Most of regions the rainfall amount with actual topography is significantly higher than with reduced topography during MAM, whereas it is almost the same during SOND. In most of regions especially in west and north provinces, the Figure 3(c) and Figure 3(f) reveal that rainfall amount with actual topography is high and less than that with reduced topography in MAM and SOND respectively. This is explained by strong winds during MAM than in SOND which transport high amount of moisture from east to west provinces as shown in Figure 4(a) and Figure 4(b). During SOND and MAM most of winds are originated from west and east of Rwanda respectively. This reveals that the direction and the intensity of winds have strong impact on spatial distribution of rainfall in

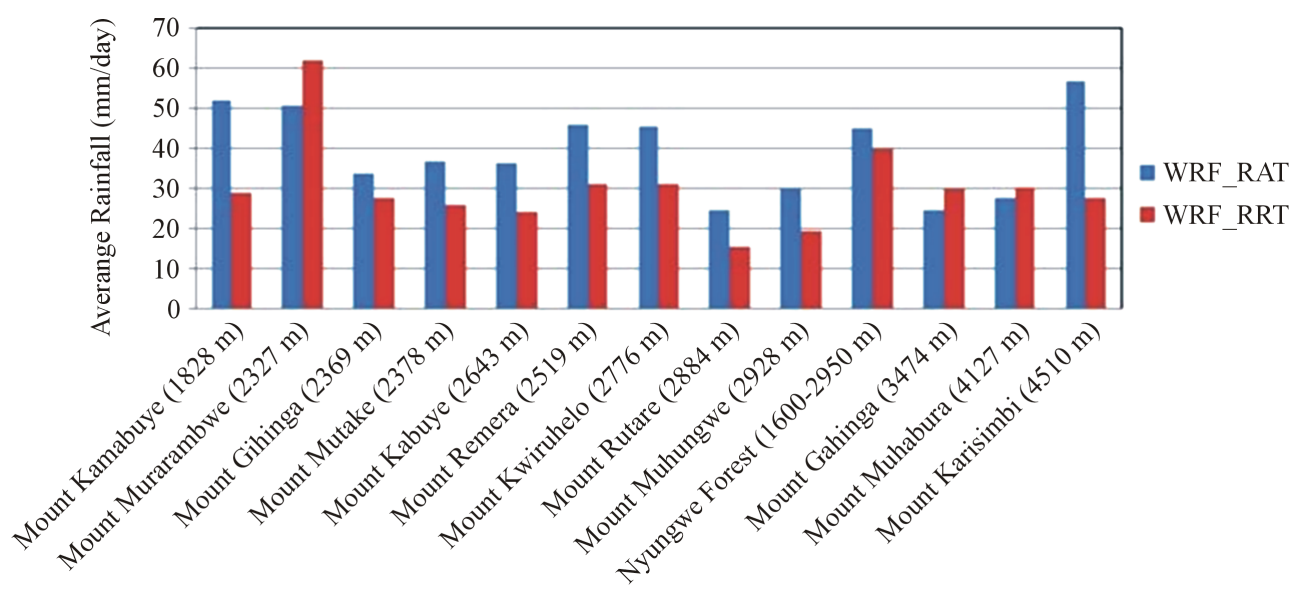

(a)

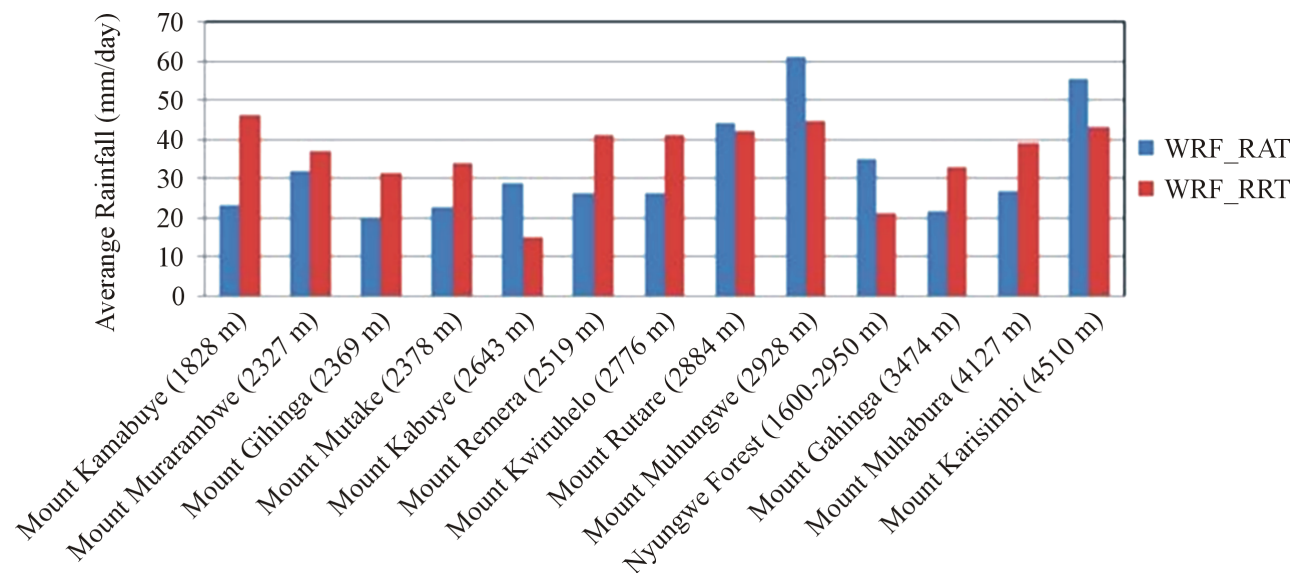

(b)

Figure 2. The mean rainfall for CASE-I (a) and CASE-II (b), showing rainfall for simulation with actual topography (WRF_RAT) and with topography reduced by half (WRF_RRT) over high altitude regions of Rwanda. 


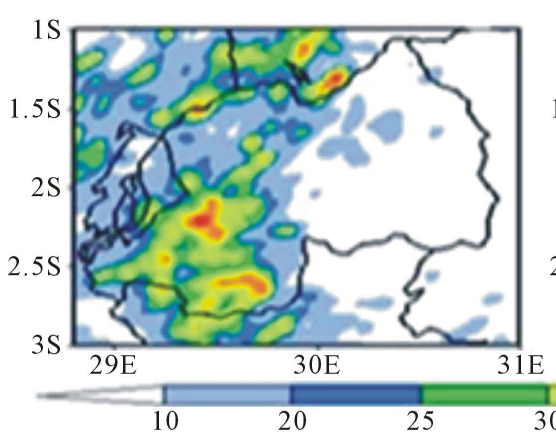

(a)

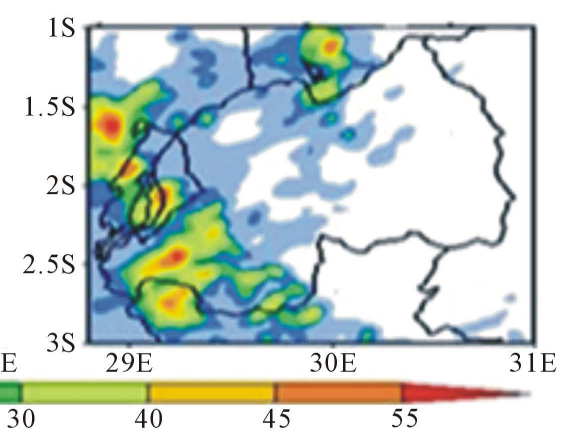

(b)

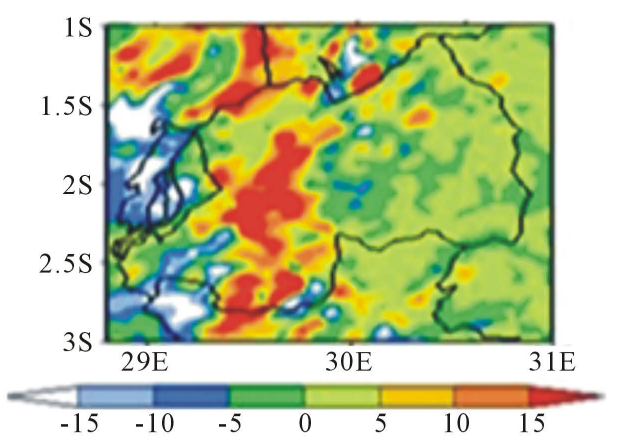

(c)
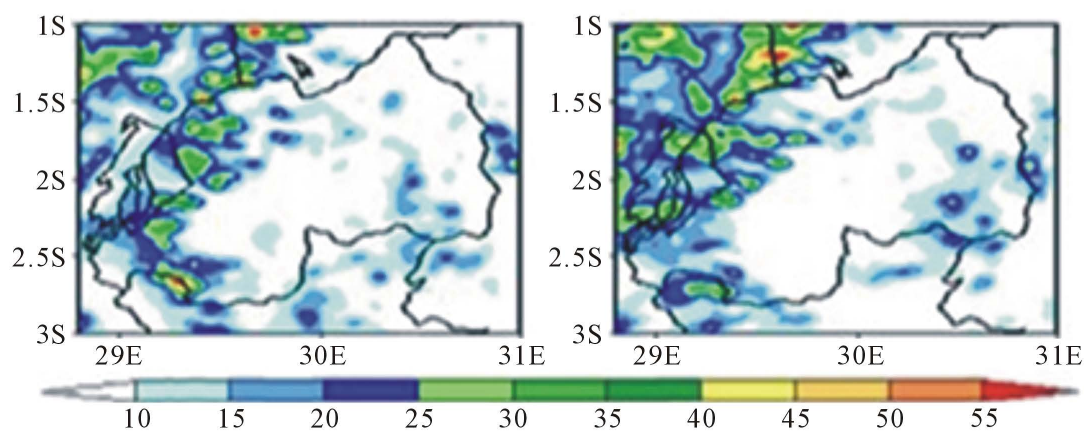

(d)

(e)

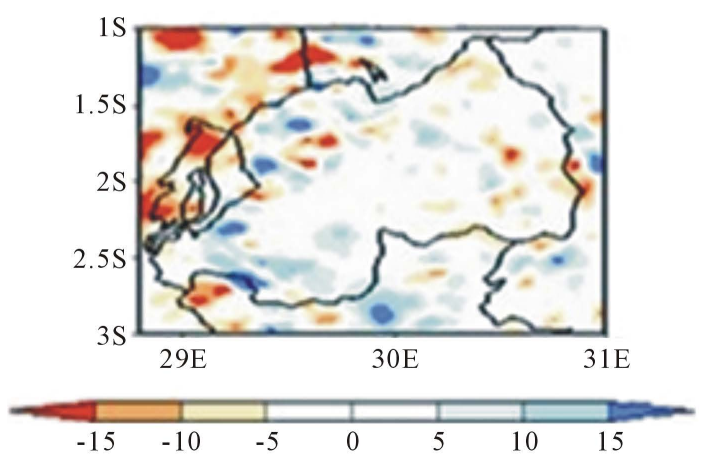

(f)

Figure 3. The accumulated rainfall (mm) for WRF with actual topography (AT) (a), (d), WRF with reduced topography (RT) (b), (e) and difference between actual and reduced topography (AT-RT) (c), (f) for the period from April 7 to 9 and October 29 to 31,2012 respectively. 
(a) MF, 7-9 APR (AT)

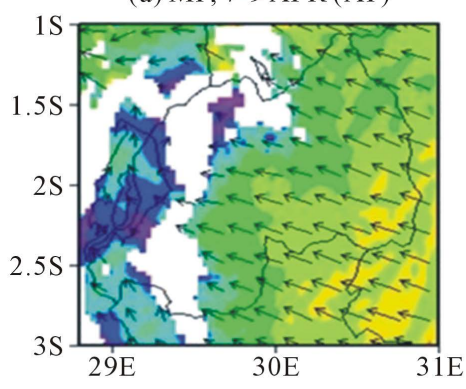

(c) MF, 29-31 OCT (AT)

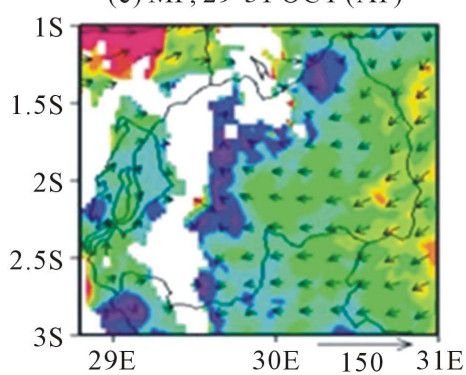

(b) MF, 7-9 APR (RT)

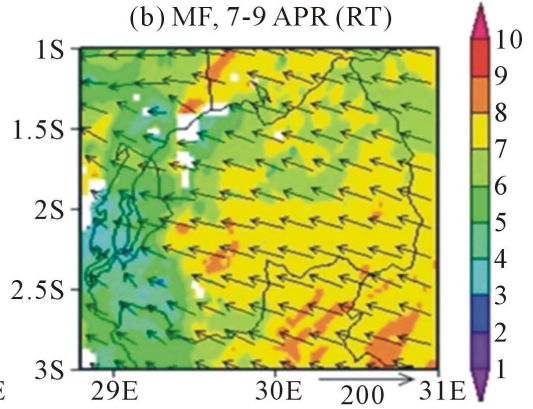

(d) MF, 29-31 OCT (RT)

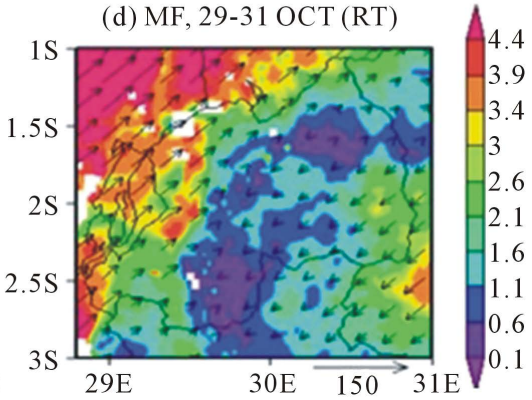

Figure 4. The mean moisture flux over the period 7 to 9 April and 29 to 31 October 2012 at 800 hpa (a), (c) with actual topography (AT), (b), (d) reduced topography (RT) respectively. The shaded area indicates magnitude of moisture, whereas vectors show moisture transport.

Rwanda. There are significant impacts on different amount of rainfall in MAM and SOND due to large amount of moisture from east and west of Rwanda respectively.

Spatial rainfall distributions (Figure 3) show that the model realistically captures the observed mean rainfall, with higher rainfall received over the western sector as opposed to the eastern sector of Rwanda. For CASE-I the difference in the mean rainfall (AT-RT) between simulation with actual topography (AT) and that with reduced topography (RT) (Figure 3(c)) shows a general reduction in rainfall in most region of Rwanda as a result of topography reduction. A small region especially between longitudes $28.8^{\circ} \mathrm{E}-29.2^{\circ} \mathrm{E}$ and latitudes $3^{\circ} \mathrm{S}-1.5^{\circ} \mathrm{S}$ shows an increase in rainfall. This variation in the rainfall distribution may be explained by the easterly and southerly moist winds from the Indian Ocean and Lake Victoria which were able to move freely after reducing topography, resulting into rainfall in regions which were previously block by the barrier due to topography. There is a general increase in rainfall after reducing topography in Western part and some of Northern part of Rwanda respectively. This shows that topography is a barrier which doesn't allow regions located in eastern province to receive much rainfall. The rainfall with actual topography is high and low than after reducing topography for CASE I (Figure 3(c)) and CASE-II (Figure 3(f)) respectively. The presence of mountains has effects on rainfall amount in mountain regions due to orographic uplifting and also they may prolong the duration of rainstorms [4]. In mountain regions the rainfall distribution is not the same on the windward and leeward sides [28].

\subsection{Moisture Transport and Vorticity}

In order to understand physical mechanisms responsible for the observed reduction and some increase in rainfall as a result of the reduction in topography elevation, we examine moisture transport and vorticity during the two cases (CASE-I and CASE-II). In East of Africa the dominant source of moisture is easterly flow from the Indian ocean especially during short rains [29]. The western regions of East Africa which are blocked by the Rift Valley slope receive moist westerly flows from the Congo basin [17]. The WRF Results show that moisture flux (MF) is transported to northern and western provinces. A major difference exists between Figure 4(a) and Figure 4(b), particularly in regions with high mountains which blocks moisture transport towards western and northern provinces. On reducing topography (Figure 4(b)), moisture is transported freely towards western, 
northern and Democratic Republic of Congo. There was convergence of southeasterly winds from Indian Ocean and westerly winds from Atlantic Ocean, Congo air mass towards Congo Nile ridge and Virunga mountains which resulted in heavy rainfall in those regions with high altitudes (Figure 4(a)). There is an increase in amount of moisture after reducing topography especially in the western sector between longitudes $28.8^{\circ} \mathrm{E}-$ $29.5^{\circ} \mathrm{E}$ (Figure 4(b)). As northern and western provinces are regions with high altitudes, 800 hpa is used as low level. The mechanism of orographic precipitation is based on the upslope ascent, where forced mechanical lifting of the air impinging on the windward side which leads to cooling of the air column, resulting in condensation and precipitation; and descent in the leeward side which leads to warming and drying where the precipitation is suppressed [30]. Winds are concentrated in northern and western province with much convergence in western province than in northern province. With actual topography the windward side is located on the right side of Congo-Nile ridge chain and Virunga Mountains which explain heavy rainfall in those regions than the lee side. Most of the winds are southeasterly which bring moisture from the Indian Ocean accompanied by the shift of ITCZ from south to north.

There was much moisture brought by easterly winds from Indian Ocean and Lake Victoria located in north-east of Rwanda. By reducing topography the moisture is uniformly distributed in most of the regions with high altitude (Congo-Nile ridge and Virunga Mountain). For CASE-II the moisture transported into Rwanda was dominated by northeasterly and southwesterly flow (Figure 4(c)). High mountains blocked the transport of moisture with actual topography but after reducing topography, the moisture is transported across most of the regions of Rwanda (Figure 4(d)), including high mountain regions. During this season, the ITCZ shifts from North to south accompanied by Atlantic and Congo air mass which converges with weak winds from east and resulted in heavy rainfall in those high altitude regions. There is strong convergence in northern province than in western province, which explains why there is much rainfall in northern province (Figure 4(a) and Figure 4(b)). There was an uplifting of air in the windward side of mountains located in the Congo Nile ridge and there was much heavy rainfall in windward side than in the leeward side of the mountain. This is due to the uplifting motion of air in the windward side which causes condensation and gives heavy rainfall and in the leeward side the air is dry and does not cause rainfall in the west side of the mountains. Further analysis shows that winds converge in the north, which may explain why rainfall amount increased over that region when topography is reduced (Figure 4(d)). The seasonal cycle of rainfall is mainly controlled by the north-south migration of the ITCZ across the region whereas the diurnal cycle is dominated by lake/land breeze circulations. The humid Congo air mass significantly boosts convection and overall rainfall amounts received over the western and northern-western parts of the Lake Victoria [31] where Rwanda is located. The upwind speed and condensation rate can be increased by the existence of convective cells within a front, probably formed in unstable layers and triggered by orographic lifting [32]. For both CASE-I and CASE-II with actual topography the moisture was blocked by high mountains which are located in northern and Western provinces (Figure 4(a) and Figure 4(c) respectively), while after reducing topography moisture was transported by winds and reach all regions especially towards North-West (Figure 4(b)) and North regions (Figure 4(d)) for CASE-I and CASE-II respectively. Southwesterly winds and magnitude of moisture is high in the north which explains heavy rainfall in northern province. When the air flows toward mountains, it can either flow up and over the mountain or slow down, or turn to flow around the mountain: a phenomenon called blocking. The scenario which occurs is dependent on the height of the topography and the resistance of air to rising. Figure 5 shows that WRF_RAT results overestimate or underestimate rain gauge stations data by region and by season. In April (Figure 5(a)) the model overestimates rain gauges in Kamembe, Gitega, Gisenyi, Busogo while underestimates at Kigali airport and Kamembe. Kawangire located in Eastern province shows good agreement with $17.36 \mathrm{~mm}$ and $14.4 \mathrm{~mm}$ by the model and rain gauge respectively. In October (Figure 5(b)) the model shows good agreement compared during April even though there are also overestimation and underestimation cases. Gikongoro located in Southern province shows good agreement with $51.44 \mathrm{~mm}$ ad $50.6 \mathrm{~mm}$ by the model and rain gauge respectively. In the recent study, the WRF model underestimated and overestimated TRMM precipitation over Lake Victoria and western side of the lake respectively [33], where Rwanda is located. In our case we used rain gauge stations data to evaluate WRF model. We found that the WRF model underestimates and overestimates rain gauges measurements in April and October differently. During April (Figure 5(a)) and October (Figure 5(a)) in Gitega station, the WRF model overestimates and underestimates rain gauges measurements whereas in Kigali Airport station it is the opposite while the same stations are not far from each other. At Gisenyi, Kamembe and Busogo stations the WRF model overestimates rain gauges measurements during both April and October. Although the 


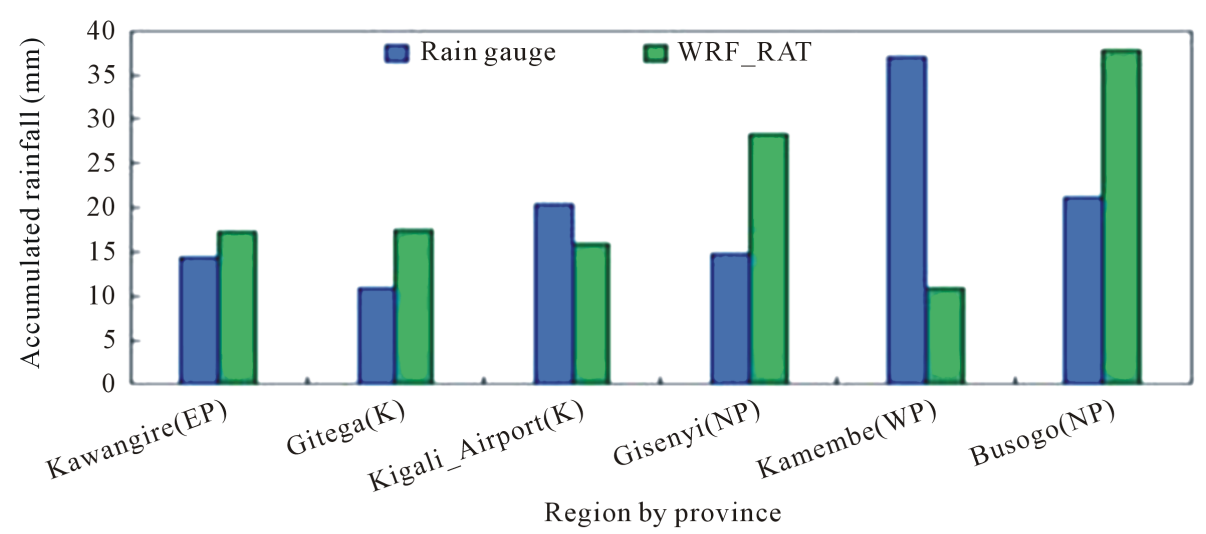

(a)

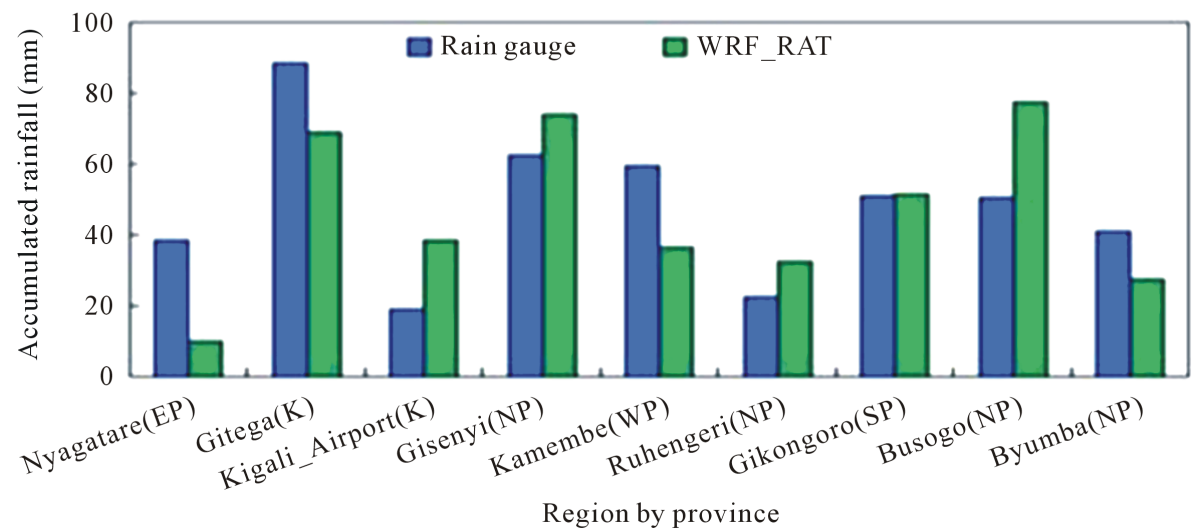

(b)

Figure 5. Rain gauge vs. WRF_RAT accumulated rainfall (mm) in northern province (NP), western province (WP), Eastern province, Southern province (SP) and Kigali in April 7 to 9, 2012 (a) and October 29 to 31, 2012 (b).

model shows overestimations in many regions, it is clear that the amount of precipitation is close to that measured by rain gauges stations especially for Kawangire, Gikongoro, and Gisenyi. Figure 5 shows that in Nyagatare and Kamembe regions with low altitudes, the model underestimates the rain gauge measurements whereas Busogo and Gisenyi regions with high altitudes the model overestimates the rain gauges. In many regions with high altitudes, the model shows close agreement with rain gauges measurements than those with low altitudes, which is the evidence that topography should be considered while using WRF model. There is a significant difference between rain gauge and WRF model in Kamembe during MAM season due to the mountains located in south-west province which act as a barrier of strong winds which transport the moisture in that region. The moisture was not able to reach the leeward side of the mountains where Kamembe is located as shown in Figure 4(a).

The WRF model parameterization while doing weather forecasting should be considered carefully in southwestern provinces where Kamembe is located during MAM. Results show that the model is too sensitive to the source and the direction of winds by the fact that most of the region where there are good agreement between the model and rain gauge are the sources of the strong winds while a significant difference in regions where strong winds are moving. During April and October most of winds with high moisture content are coming from Eastern province and Northern province respectively.

\section{Summary and Conclusion}

This study was aimed at investigating the impact of topography on heavy rainfall during two rain seasons in order to explain the mechanisms of topographic influence on rainfall distribution over Rwanda. Two regions 
(western and northern provinces) were considered because of their high altitude. Weather Research and Forecasting (WRF-ARW) model was used to study two historical cases of heavy rainfall which took place over Rwanda during two rain seasons, March to May (MAM) and September to December (SOND), from April 7 to 9, 2012 (for MAM) and from October 29 to 31, 2012 (during SOND). The findings reveal that the rainfall amount during MAM (CASE I) and SOND (CASE II) with actual topography (AT) and reduced topography (RT) are not the same. In most of the regions the rainfall before reducing topography (i.e. with actual topography) is much less than that after reducing topography. There were strong easterly winds from Indian Ocean converges with southerly and westerly winds which resulted to heavy rainfall during MAM. Strong westerlynortherly winds coming from Atlantic Ocean and accompanied by Congo air mass converge with weak easterly northerly winds from Lake Victoria which resulted on heavy rainfall during SOND. The east sides of the Congo Nile ridge and Virunga mountains (in western and northern provinces) have high amount of rainfall during MAM and less amount during SOND. The west sides of the Congo Nile ridge and Virunga mountains have less amount of rainfall during MAM and high of rainfall during SOND. The WRF model shows the ability to detect the sensitivity of heavy rainfall to the presence of the mountains and other high peaks in northern and western regions. After reducing topography by half, there was a significant modification in rainfall amount due to the orographic uplifting processes in all days considered. Rwanda heavy rainfall occurs as air mass of various origins converges. The impacts of topography during long rain season (MAM) and that of short rains season (SOND) are not the same due to the position and the shift of ITCZ during those seasons. Almost all orographic influences are fundamentally caused by topographically driven ascending and descending atmospheric motions that force condensation and evaporation. The comparison between the WRF model and rain gauge reveals that the configuration should be done by considering the direction and source of winds by season. Further studies need to be done by using different model parameterization schemes by considering season and region. We note that WRF model is good tool to be used in high altitude regions for rainfall forecasting where no ground data are still unavailable.

\section{Acknowledgements}

The authors are grateful to the Institute of Atmospheric Physics, University of Chinese Academy of Sciences (CAS), Nanjing University of Information, Science and Technology (NUIST) for providing the required facilities for modeling and data analysis. We would also to thank Prof. Min Jinzhong for his helpful suggestions, fruitful comments and his time to revise this work. The financial support by WMO (World Meteorological Organization), Chinese government and CAS-TWAS is highly appreciated. We also thank reviewers for their time, thoughtful and insightful comments.

\section{References}

[1] Sun, L., Semazzi, F. H. M., Giorgi, F. and Ogallo, L. (1999) Application of the NCAR Regional Climate Model to Eastern Africa: 1. Simulation of the Short Rains of 1988. Journal of Geophysical Research, 104, 6529-6548.

[2] McSweeney, R., Cole, M., Semafara, J.N. and Washington, R. (2011) Rwanda's Climate: Observations and Projections, Appendix E. Smith School of Enterprise (SSEE) and the Environment, University of Oxford, Oxford.

[3] Gerald, H.R. (2005) Orographic Precipitation. Annual Review of Earth and Planetary Sciences, 33, 645-671. http://dx.doi.org/10.1146/annurev.earth.33.092203.122541

[4] Thomas, K.F. and Gerhard, W.R. (2012) WRF Model Simulation of Two Alberta Flooding Events and the Impact of Topography. Journal of Hydrometeorology, 13, 695-708. http://dx.doi.org/10.1175/JHM-D-11-035.1

[5] Smith, R.B. (1979) The Influence of Mountains on the Atmosphere. Advances in Geophysics, 21, 87-230.

[6] Basist, A., Gerald, D.B. and Meentemeyer, V. (1993) Statistical Relationship between Topography and Precipitation Patterns. Journal of Climate, 7, 1305-1315. http://dx.doi.org/10.1175/1520-0442(1994)007<1305:SRBTAP>2.0.CO;2

[7] Anyah, R.O. and Semazzi, F.H.M. (2004) Simulation of the Sensitivity of Lake Victoria Basin Climate to Lake Surface Temperatures. Theoretical and Applied Climatology, 79, 55-69.

[8] Hayward, D. and Clarke, R.T. (1996) Relationship between Rainfall, Altitude and Distance from the Sea in the Freetown Peninsula, Sierra Leone. Hydrological Sciences Journal, 41, 377-384.

[9] Stager, J.C., Reinthal, P.N. and Livingstone, D.A. (1986) A 25,000-Year History of Lake Victoria, East Africa, and Some Comments on Its Significance for the Evolution of Cichlid Fishes. Freshwater Biology, 16, 15-19. http://dx.doi.org/10.1111/j.1365-2427.1986.tb00944.x 
[10] King, D., Byamukama, B., Carey, C., Cole, M., Dyszynski, J., Blowfield, Eyre, M.N, Frame, D., Gupta, R., Heffernan, C., Hepburn, C., Inderwildi, O., New, M., Pearce, G., Pickett, J., Rajan, R. and Washington, R. (2011) National Strategy on Climate Change and Low Carbon Development for Rwanda. http://cdkn.org/wp-content/uploads/2010/12/FINAL-Baseline-Report-Rwanda-CCLCD-Strategy-super-low-res.pdf

[11] Khalid, A.A. and Sharaf, A.A. (2013) Rainfall-Altitude Relationship in Saudi Arabia. Advances in Meteorology, 2013, Article ID: 363029.

[12] Bonacina, L.C.W. (1945) Orographic Rainfall and Its Place in the Hydrology of the Globe. Quarterly Journal of the Royal Meteorological Society, 71, 41-45. http://dx.doi.org/10.1002/qj.49707130705

[13] Jimenez, J.A. and Dudhia, J. (2013) On the Ability of the WRF Model to Reproduce the Surface Wind Direction over Complex Terrain. Journal of Applied Meteorology and Climatology, 52, 1610-1617. http://dx.doi.org/10.1175/JAMC-D-12-0266.1

[14] Gamal, E.A., Mostafa, M. and Fathy, E.H. (2012) Heavy Rainfall Simulation over Sinai Peninsula Using the Weather Research and Forecasting Model. International Journal of Atmospheric Sciences, 2013, Article ID: 241050.

[15] Skamarock, W.C. and Weisman, M.L. (2008) The Impact of Positive-Definite Moisture Transport on NWP Precipitation Forecasts. Monthly Weather Review, 137, 488-494. http://dx.doi.org/10.1175/2008MWR2583.1

[16] Obasi, G.O.P. (2005) The Impacts of ENSO in Africa. In: Low, P.S., Ed., Climate Change and Africa, Cambridge University Press, Cambridge, 218-230.

[17] Flaounas, E., Basin, S. and Janicot, S. (2010) Regional Climate Modeling of the 2006 West African Monsoon: Sensitivity to Convection and Planetary Boundary Layer Parameterization Using WRF. Climate Dynamics, 36, 1083-1105. http://dx.doi.org/10.1007/s00382-010-0785-3

[18] Hession, S.L. and Moore, N. (2011) A Spatial Regression Analysis of the Influence of Topography on Monthly Rainfall in East Africa. International Journal of Climatology, 31, 1440-1456. http://dx.doi.org/10.1002/joc.2174

[19] Teixeira, J.C., Carvalho, A.C., Luna, T. and Rocha, A. (2014) Sensitivity of the WRF Model to the Lower Boundary in an Extreme Precipitation Event-Madeira Island Case Study. Natural Hazards and Earth System Sciences Discussions, 1, 5603-5641. http://dx.doi.org/10.5194/nhessd-1-5603-2013

[20] Mohan, M. and Sati, A.P. (2016) WRF Model Performance Analysis for a Suite of Simulation Design.

[21] Megan, S.G. and Lackmann, G.M. (2010) Sensitivity of Simulated Tropical Cyclone Structure and Intensity to Horizontal Resolution. Monthly Weather Review, 138, 688-704. http://dx.doi.org/10.1175/2009MWR2976.1

[22] National Centre for Atmospheric Research (NCAR) (2014) ARW Version 3 Modeling System's User's Guide. NCAR, Boulder.

[23] Michalakes, J., Dudhia, J., Gill, D., Henderson, T., Klemp, J., Skamarock, W. and Wang, W. (2004) The Weather Research and Forecast Model: Software Architecture and Performance. Proceeding of the 11th ECMWF Workshop on the Use of High Performance Computing in Meteorology, Reading, 25-29 October 2004, 156-168.

[24] Skamarock, W., Klemp, J., Dudhia, J., Gill, D. and Barker, D. (2008) A Description of the Advanced Research WRF version 3. NCAR Technical Note NCAR/TN-475+STR, 113 p.

[25] Maussion, F., Scherer, D., Finkelnburg, R., Richters, J., Yang, W. and Yao, T. (2011) WRF Simulation of a Precipitation Event over the Tibetan Plateau, China-An Assessment Using Remote Sensing and Ground Observations. Hydrology and Earth System Sciences, 15, 1795-1817. http://dx.doi.org/10.5194/hess-15-1795-2011

[26] Benjamin, P.C.J. and Pierre, C. (2011) Testing WRF Capability in Simulating the Atmospheric Water Cycle over Equatorial East Africa. Climate Dynamics, 37, 1357-1379. http://dx.doi.org/10.1007/s00382-011-1024-2

[27] Jessica, E.T., Jason, E.S., Kevin, J.A. and Richard, S. (2013) Multidecadal Variability in East African Hydroclimate Controlled by the Indian Ocean. Nature, 493, 389-392. http://dx.doi.org/10.1038/nature11785

[28] Anyamba, E.K. (1984) Some Aspects of the Origin of Rainfall in Deficiency in East Africa. Proceedings of the WMO Regional Scientific Conference on GATE, WAMEX and Tropical Meteorology, Dakar, 10-14 December 1984, 110-112.

[29] Black, E., Slingo, J. and Sperber, K.R. (2003) An Observational Study of the Relationship between Excessively Strong Short Rains in Coastal East Africa and Indian Ocean SST. Monthly Weather Review, 131, 74-94. http://dx.doi.org/10.1175/1520-0493(2003)131<0074:AOSOTR>2.0.CO;2

[30] Browning, K.A., Hill, F.F. and Pardoe, C.W. (1974) Structure and Mechanism of Precipitation and the Effect of Orography in a Wintertime Warm Sector. Quarterly Journal of the Royal Meteorological Society, 100, 309-330. http://dx.doi.org/10.1002/qj.49710042505

[31] Johansson, B. and Chen, D. (2003) The Influence of Wind and Topography on Precipitation Distribution in Sweden: Statistical Analysis and Modeling. International Journal of Climatology, 23, 1523-1535.

http://dx.doi.org/10.1002/joc.951 
[32] Anders, A.M., Roe, G.H., Hallet, B., Montgomery, D.R., Finnegan, N.J. and Putkonen, J. (2006) Spatial Patterns of Precipitation and Topography in the Himalaya. In: Willett, S.D., Hovius, N., Brandon, M. and Fisher, D.M., Eds., Tectonics, Climate, and Landscape Evolution: GSA Special Paper 398, Geological Society of America, Boulder, 39-53. http://dx.doi.org/10.1130/2006.2398(03)

[33] Argent, R., Sun, X., Semazzi, F., Xie, L. and Liu, B. (2015) The Development of a Customization Framework for the WRF Model over the Lake Victoria Basin, Eastern Africa on Seasonal Timescales. Advances in Meteorology, 2015, Article ID: 653473. http://dx.doi.org/10.1155/2015/653473 